Suppose now $\mathrm{F}$ to be so large, positive or negative, as to make $v$ so great that $\mathrm{V}$ may be neglected in comparison with it, then we may think of the cups as whirled round in quiescent air in the positive or usual direction when $\mathrm{F}$ is negative, in the negative direction when $F$ is greater than $F_{1}$. When $F$ is sufficiently large the resistance may be taken to vary as $v^{2}$. For equal velocities $v$ it is much greater when the concave side goes foremost than when the rotation is the other way. For air impinging perpendicularly on a hemispherical cup Dr. Robinson found that the resistance was as nearly as possible four times as great when the concave side was directed to the wind as when the convex side was turned in that direction (Transactions of the Royal Irish Academy, vol. xxii. p. I63). When the air is at rest and the cups are whirled round, some little difference may be made by the wake of each cup affecting the one that follows. Still we cannot be very far wrong by supposing the same proportion, 4 to $I$, to hold good in this case. When $F$ is large enough and negative, $F$ may be taken to vary as $v^{2}$, say to be equal to $-L v^{2}$. Similarly, when $\mathrm{F}$ is large enough and positive, $\mathrm{F}$ may be taken equal to $L^{\prime} v^{2}$, where in accordance with the experiment referred to, $L^{\prime}$ must be about equal to $4 \mathrm{~L}$. Hence we must have nearly-

$$
\eta=-\mathrm{L} \xi^{2} \text {, when } \xi \text { is positive and very large ; }
$$

$$
\eta=4 \mathrm{~L} \xi^{2}, \quad, \quad \text { negative ,", }
$$

Hence if we draw the semi-parabola $O \mathrm{AB}$ corresponding to the equation $\eta=4 \mathrm{~L} \xi^{2}$ in the quadrant $\eta 0-\xi$, and the semi-parabola O C D with a latus lectum four times as great in the quadrant $\xi \circ-\eta$, our curve at a great distance from the origin must nearly follow the parabola $O A B$ in the quadrant $\eta \mathrm{O}-\xi$, and the parabola $O C D$ in the quadrant $\xi O-\eta$, and between the two it will have some flowing form such as P N M K. There must be a point of inflection somewhere between $\mathrm{P}$ and $\mathrm{K}$, not improbably within the positive quadrant $\xi \circ \eta$. In the neighbourhood of this point the curve $\mathrm{N}$ M would hardly differ from a straight line. Perhaps this may be the reason why Dr. Robinson's experiments in the paper published in the Phil. Trans. for 1878 were so nearly represented by a straight line.

\section{FELLOWSHIPS AT OWENS COLLEGE, MANCHESTER}

A SCHEME of Science and Literature Fellowships, modelled very closely after the pattern of the Fellowship Scheme of the Johns Hopkins University, Baltimore, has been organised in Owens College, Manchester. The Council propose, early in October next, to appoint to five Fellowships on the terms and conditions following :-1. The appointment will be made by the Council, after receiving a report from the Senate, not on the results of examination, but after consideration of documentary or other evidence furnished to them. 2. Application by persons desiring to hold these fellowships must be made, in writing, on or before October 1. In his application the candidate should indicate the course of his previous reading and study, and his general purposes with reference to future work. 3. The candidate must give evidence of having received a sound and systema tic education either in literature or in science, such as the possession of a degree of an English University, or a certificate from the authorities of an English School of Medicine or Science, of good repute, showing that he has passed through his curriculum with distinction, or, in default thereof, such other evidence as shall be satisfactory to the Council that he is qualified to prosecute some special study or investigation in the manner indicated in $\S 6$. Finally, he should produce a satisfactory testimonial of character and conduct, and should give the names of not more than three persons from whom further information may be sought. 4. In the award of the Fellowships regard will be had to the pecuniary circumstances of the candidates. 5. The value of each Fellowship will be $100 l$. for the academical year $188 \mathrm{I}-82$. In case of resignation or other withdrawal from the Fellowship, payment will be made for the time during which the Fellowship may have been actually held. 6. Every holder of a Fellowship will be expected to devote his time to the prosecution of some special study, with the approval of the Council after receiving a report from the Senate; and before the close of the year to give evidence of progress by the preparation of a thesis, the delivery of a lecture, the completion of some research, or in some other method. He will study under the direction of the Professor of the subject in which he is appointed, and will be required to pay such fees as the Council shall in each case determine. 7. He may be called on by the Council, after report from the Senate, to render some service to the College, either as an occasional examiner or by giving instruction in lectures or otherwise, to students in the College-provided always that he shall not, during his tenure of the Fellowship, hold any regular or salaried post as Assistant Lecturer or Demonstrator in the College-but he may not engage in teaching elsewhere. 8 . He must reside in Manchester during the academical year. 9. He may be re-appointed at the end of the Session for a second and, in like manner, for a third year. Io. Candidates are invited to apply for appointment in any one of the following nine departments :-(1) Classics; (2) English Language and Literature; (3) History ; (4) Philosophy ; (5) Pure Mathematics; (6) Applied Mathematics (including Engineering); (7) Physics; (8) Chemistry ; (9) Biology (including Physiology)

\section{SOCIETIES AND ACADEMIES$$
\text { LONDON }
$$

Royal Society, June I6. - "On Stratified Discharges. VI. Shadows of Striæ," by William Spottiswoode, P.R.S., and J. Fletcher Moulton, F.R.S.

One of the most interesting questions connected with the sub. ject of stratified discharges is this: What is the physical, as distinguished from the electrical, nature of the striæ themselves? Are they, in fact, to be regarded as aggregations of matter possessing greater density than the gas present in the dark spaces, or are they to be considered as indicating merely special local electrical conditions? The fact of their having a definite configuration, especially on the side which is turned towards the negative terminal of the tube, that of their temperature being higher than that of the dark spaces, the manner in which they are affected by solid bodies, and other considerations, all tend to give support to the view that the strix are loci of greater density than the dark spaces. Still it can hardly be said that as yet any experimental proof of this has been given sufficiently decisive to decide the question conclusively. And it is in the hope of contributing something towards the solution of this question that the following experiments are submitted to the notice of the Royal Society.

The two terminals of a Holtz machine were connected in the usual way with the two terminals of the tube, so as to produce a stratified discharge. A narrow strip of tin-foil, or a wire, was stretched along the tube opposite the column of striæ. The positive terminal of a second Holtz machine (in practice we used for this purpose a Töppler machine) was connected with the tin-foil, and the negative terminal with one (either) terminal of the tube. An air-spark, or interval across which sparks could pass, was interposed in the part of the circuit between the machine and the tin-foil. The effect of this arrangement was this: In the interval between two sparks the tin-foil and tube became charged like a Leyden jar; the tin-foil being the outer coating, charged positively, and the gas inside serving as the inner coating, charged negatively. When the spark passed across the interval mentioned above, the jar (i.e. the tube) became discharged, and the electricity previously held bound on the two coatings was set free.

When the first (say the "internal") machine was not working, or when it was disconnected, i.e., when no regular discharge was passing through the tube, then, whenever a spark passed at the second (or " external") machine, a negative discharge with its accompanying Crookes' radiation took place from the inside of the tube next the tin-foil, and the opposite side of the tube became covered with a sheet of green phosphorescence (the tube being of German glass).

When, however, other things remaining as before, a discharge from the internal machine was sent through the tube, and a good stratified column was produced, it was found that the green phosphorescence was entirely cut off from the parts of the tube opposite to the striæ, while on the parts opposite to the dark spaces it remained, in the form of phosphorescent rings, as brilliant as before. The experiment was repeated with various tubes with various degrees of strength of current, and with various densities of gas (produced by heating a chamber of potash in connection with the tube). It may be added that when, as is sometimes the case, through greater exhaustion, the striæ became feebler in illumination and less compact in appearance, the shadows cast by them lost proportionally in sharpness of definition and in completeness of extinction of the phosphorescent light.

The brilliancy and definition of the phosphorescent rings may be increased by inserting a small Leyden jar in the circuit, care being taken that the jar shall discharge itself completely each time. If this is not the case the main discharge is followed by 